\title{
Optimal diameters of triple concentric-tube heat exchangers
}

\author{
Achour Touatit, Cherif Bougriou \\ Mechanical Engineering Department, Faculty of Technology, University of Batna 2, Algeria
}

Corresponding Author Email: c.bougriou@univ-batna2.dz

https://doi.org/10.18280/ijht.360149

Received: 7 July 2017

Accepted: 20 March 2018

\author{
Keywords: \\ heat exchanger, concentric-tube, design, \\ energy, cost.
}

\begin{abstract}
A Fortran code of calculation is used to determine the temperature profiles of three fluids, as well the various heat transfer coefficients, the total frictional power expenditure in a triple concentric-tube heat echanger in steady state. The system is composed of three concentric tubes, hydrogen flows into the central tube, nitrogen passes through the inner annulus and oxygen flows into the outer annulus passage in cocurrent and counter-current flows. The thermophysical properties used in this study are supposed variables with the temperature. We use in this study a techno-economic method to optimize the heat exchanger by determining the optimal diameter corresponding to the minimal total cost of the heat exchanger (functioning and investment). Now we have only one optimum tube diameter for each heat exchanger which corresponds to the minimum total cost of the heat exchanger (total frictional power expenditure and the fabrication of the heat exchanger), unlike previous studies in the literature, where we had two optimal tube diameters: the first corresponds to the maximal heat exchanger efficiency and the last one to the minimal energy consumption required to overcome the pressure drop in the heat exchanger.
\end{abstract}

\section{INTRODUCTION}

The hydrogen engine in a hypersonic vehicle propulsion system can be composed of three concentric tubes wherein hydrogen is reactive with oxygen to be conditioned, a leak safe arrangement of concentric tubes disposed across the conditioned fluid flow (oxygen) path having the hydrogen in a central tube surrounded by nitrogen in the inner annulus so that single failure leak of hydrogen or nitrogen presents no risk of harmful reaction with oxygen [1-4]. Due to the wide use of heat exchangers in different processes, minimization their cost is very important for designers and users. This type of heat exchangers can be used for the cooling of nitrogen and oxygen (air) since it operates with three fluids. In this study, we propose a method for optimum design of triple concentric-tube heat exchangers, using a computer program (TTC) written in Fortran in order to minimize the cost of the device. The total cost is the sum of the investment cost (heat exchanger construction) and operating cost (annual energy costs for pumping and maintenance).

The major contribution of researchers from literature, are as follows. Zuritz [5] performed a set of analytical equations for fluid temperatures of a triple concentric-tube heat exchanger. Unal [6-8] have treated a case study for the counter-current arrangement based on a simplified physical model with a fully analytical expression for the variations of the bulk temperatures of the three fluids streams along the triple concentric-tube heat exchanger. A series of case studies for counter-current arrangement proved that the heat exchanger performance or size is dependent on the relative sizes of the diameters of the three tubes. The previously temperature distribution expressions have been completed with a fully analytical expression for the effectiveness of triple concentrictube heat exchangers with both the counter-current and co- current arrangements. Garcia-Valladares [9] studied a onedimensional numerical model of the thermal performance of the triple concentric-tube heat exchangers, in both transient and steady states. The efficiency comparison between Solar Parabolic Trough Collector (PTC) with double pass and with single pass was carried out by Garcia-Valladares and Velazquez [10]. Nema et al. [11] suggested various models for the prediction of fouling thickness and milk outlet temperature in a triple helical tube heat exchanger. Helical triple tube heat exchanger was numerically studied by Sahoo et al. [12], this study was limited to investigate the milk fouling factor and discussed the influencing parameters. Batmaz et al. [13] determined the overall heat transfer coefficients in a triple concentric-tube heat exchanger. The temperature profiles of all streams in a triple concentric-tube heat exchanger in the axial direction were given. Batmaz et al. [14] developed a new procedure and utilized the overall heat transfer coefficients of a triple tube heat exchanger. The axial temperature distribution of fluids was computed for a cooling process for different flow rates and inlet temperatures of the fluid streams. Caputo et al. [15] used a new procedure for the optimal design of the shell and tube heat exchanger. They proposed a genetic algorithm to minimize the total cost of equipment, including investments capital and annual fees spent for pumping. Caputo et al., have achieved significant cost reductions (saving more than $50 \%$ ). An experimental investigation was conducted by Lee et al. [16] to explore the validity of classical correlations based on conventional sized channels for predicting the thermal behaviour in single phase flow through rectangular microchannel. Başal et al. [17] proposed a numerical study of a new type of thermal energy storage system consisting of a triple concentric-tube heat exchanger. The phase change material (PCM) annulus is in contact with both inner and outer surfaces of the heat exchanger, that provide a larger heat 
transfer area. The performance of a triple concentric-pipe heat exchanger under steady state conditions for different flow arrangements was experimentally studied by Quadir et al. [18]. Quadir et al. [19] carried out a numerical study using finite element for different flow arrangements and for insulated and non-insulated conditions of the triple tube heat exchanger. Singh et al. [20] studied experimentally the thermo-hydraulic behaviour of a triple tube heat exchanger for different flow arrangements. Patrascioiu et al. [21] developed a numerical model for predicting the outlet temperatures in a triple tube heat exchanger. Abdalla et al. [25-26] are investigated experimentally and numerically the triple concentric-tube heat exchanger to present a clear view on the thermo-fluid characteristics of this type of heat exchangers with different key design parameters leading to design optimization, to evaluate the performance characteristics of the triple concentric-tube heat exchanger with rib inserts. A numerical model of a three concentric tubes combustion chamber was developed and investigated to evaluate its thermal performances by Valerio et al. [27]. An experimental investigation to evaluate the performance characteristics of the triple concentric-tube heat exchanger with inserted coiled tube is studied by Taraprasad et al. [28].

The aim of this numerical study is to find only one optimal tube diameter of the triple concentric-tube heat exchanger, corresponding to the minimum total cost of the heat exchanger (total frictional power expenditure and fabrication of the heat exchanger). In the previous studies [6-8], we had two different optimal tube diameters, the first diameter corresponds to the maximum heat exchanger efficiency and the second diameter corresponds to the minimal energy consumption required to overcome the pressure drop in the heat exchanger.

The thermophysical properties used in this study are supposed variables with the temperature.

This paper is organized as follows. Section 2 presents the calculation of the triple concentric-tube heat exchanger. Section 3 presents the results and a conclusion.

\section{CALCUlation OF THE TRIPLE CONCENTRIC- TUBE HEAT EXCHANGER}

The Number of Transfer Units $(N T U)$ method is used for the heat exchanger calculation. This method bases on the definition of the maximum transferable thermal flow on one hand and the heat exchanger efficiency on the other hand.

The studied heat exchanger, of length $L$ consists of three concentric tubes. The cold fluid (hydrogen) circulates in the internal tube, the oxygen flows in the outside annular passage and the nitrogen passes in the internal annulus passage.

For the mathematical formulation of our studied problem, we make the following hypotheses

1- Steady-state operating regime.

2- Monophasic and incompressible fluids.

3- Thermophysical properties of the fluids depend on the temperature.

4- Completely insulated heat exchanger.

5- Constant cross sections.

6- Unimportant thermal conduction in the fluid.

The energy balances in the triple concentric-tube heat exchanger is given by:

$\Phi_{\mathrm{T}}=\mathrm{m}_{2} \mathrm{Cp}_{2} \Delta \mathrm{T}_{2}=\mathrm{m}_{1} \mathrm{Cp}_{1} \Delta \mathrm{T}_{1}+\mathrm{m}_{3} \mathrm{Cp}_{3} \Delta \mathrm{T}_{3}$

\subsection{Main temperatures}

The main necessary temperatures for the sizing of a triple concentric-tube heat exchanger are schematized on figures 1 and 2 .

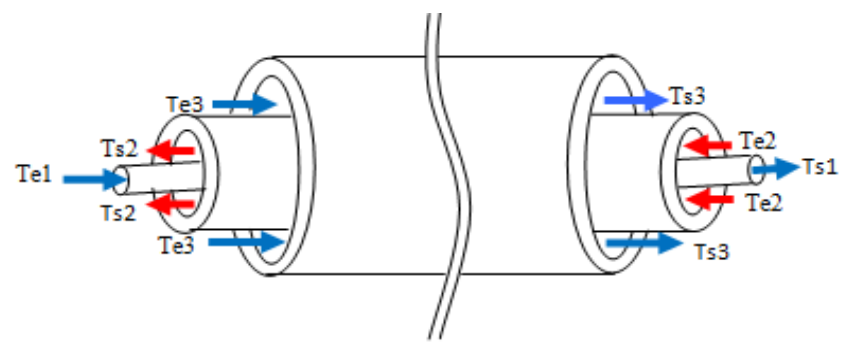

Countercurrent flow

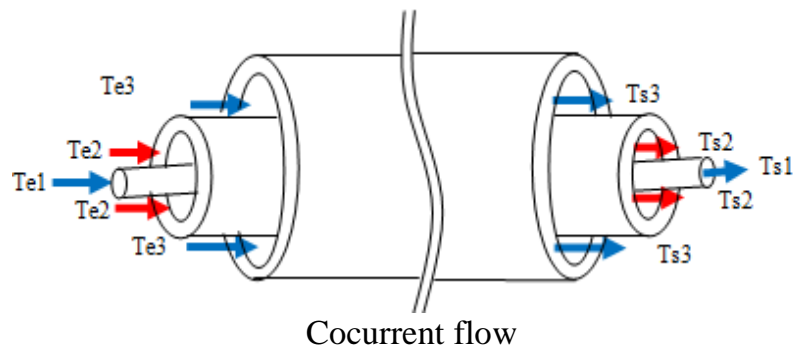

Figure 1. Triple concentric-tube heat exchanger

\subsection{Maximum heat flux}

The maximum transferable heat flux by a triple concentrictube heat exchanger are reached for an infinitely long heat exchanger. In such configuration, one of the fluids undergoes the highest rise or the highest reduction of temperature.

$$
\begin{aligned}
\Phi_{\mathrm{I}, \max } & =\min \left(\mathrm{m}_{1} \mathrm{Cp}_{1}, \mathrm{~m}_{2} \mathrm{Cp}_{2}\right) \Delta \mathrm{T}_{\mathrm{I}, \max } \\
\Phi_{\mathrm{II}, \max } & =\min \left(\mathrm{m}_{3} \mathrm{Cp}_{3}, \mathrm{~m}_{2} \mathrm{Cp}_{2}\right) \Delta \mathrm{T}_{\mathrm{II}, \max }
\end{aligned}
$$

\subsection{Heat exchanger efficiency}

The heat exchanger efficiency is a dimensionless number less or equal of the unity $(0 \leq \mathbf{E} \leq 1)$.

$$
\begin{aligned}
& \mathrm{E}_{\mathrm{I}}=\max \left(\Delta \mathrm{T}_{1}, \Delta \mathrm{T}_{2}\right) / \Delta \mathrm{T}_{\mathrm{I}, \max } \\
& \mathrm{E}_{\mathrm{II}}=\max \left(\Delta \mathrm{T}_{2}, \Delta \mathrm{T}_{3}\right) / \Delta \mathrm{T}_{\mathrm{II}, \max }
\end{aligned}
$$

\subsection{Heat capacity ratio}

According to the case of the fluid which commands the transfer, the expressions of the heat capacity ratio are given by:

$$
\begin{aligned}
& \left\{\begin{array}{l}
\mathrm{Z}_{\mathrm{I}}=\min \left(\mathrm{C}_{1}, \mathrm{C}_{2}\right) / \max \left(\mathrm{C}_{1}, \mathrm{C}_{2}\right) \\
\mathrm{Z}_{\mathrm{II}}=\min \left(\mathrm{C}_{2}, \mathrm{C}_{3}\right) / \max \left(\mathrm{C}_{2}, \mathrm{C}_{3}\right)
\end{array}\right. \\
& \left\{\begin{array}{l}
\min \left(\Delta \mathrm{T}_{1}, \Delta \mathrm{T}_{2}\right) / \max \left(\Delta \mathrm{T}_{1}, \Delta \mathrm{T}_{2}\right) \\
\mathrm{Z}_{\mathrm{II}}=\min \left(\Delta \mathrm{T}_{2}, \Delta \mathrm{T}_{3}\right) / \max \left(\Delta \mathrm{T}_{2}, \Delta \mathrm{T}_{3}\right)
\end{array}\right.
\end{aligned}
$$




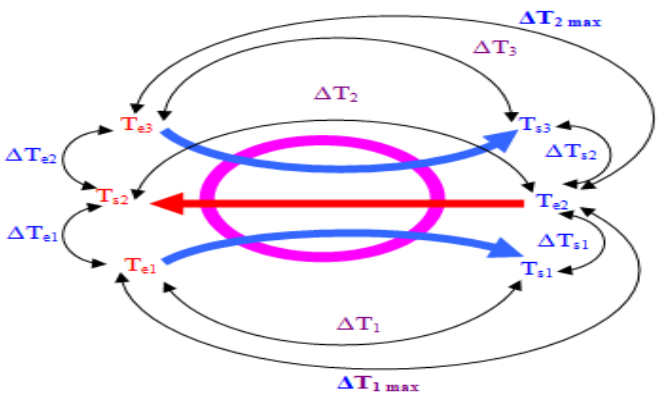

Countercurrent flow

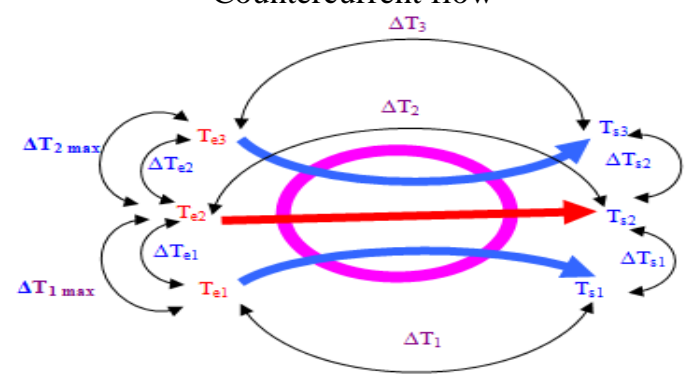

Cocurrent flow

Figure 2. Main temperatures in a triple concentric-tube heat exchanger.

\subsection{Number of transfer unit}

The number of transfer unit is a dimensionless number. It represents the relationship between the thermal conductance and the minimal heat capacity of the fluid:

$$
\begin{aligned}
& \mathrm{NUT}_{\mathrm{I}}=\left(\mathrm{K}_{\mathrm{I}} \mathrm{S}_{1}\right) / \min \left(\mathrm{C}_{1}, \mathrm{C}_{2}\right) \\
& \mathrm{NUT}_{\text {II }}=\left(\mathrm{K}_{\text {II }} \mathrm{S}_{2}\right) / \min \left(\mathrm{C}_{2}, \mathrm{C}_{3}\right)
\end{aligned}
$$

\subsection{Expression of the efficiency (E) according to ( $Z$ and} NTU)

We can thus use the valid general expression in every case.

\subsubsection{Countercurrent flow}

$$
\begin{aligned}
& N U T_{I I}=\frac{1}{1-Z_{I I}} \ln \frac{1-Z_{I I} E_{I I}}{1-E_{I I}} \\
& E_{I}=\frac{1-\exp \left[\left(1-Z_{I}\right) N U T_{I}\right]}{1-Z_{I} \exp \left[\left(1-Z_{I}\right) N U T_{I}\right]} \\
& N U T_{1}=\frac{1}{1-Z_{I}} \ln \frac{1-Z_{I} E_{I}}{1-E_{I}}
\end{aligned}
$$

$$
E_{I I}=\frac{1-\exp \left[\left(1-Z_{I I}\right) N U T_{I I}\right]}{1-Z_{\text {II }} \exp \left[\left(1-Z_{\text {II }}\right) N U T_{I I}\right]}
$$

\subsubsection{Cocurrent flow}

$$
N U T_{I I}=\frac{1}{1+Z_{I I}} \ln \frac{1}{1-E_{I I}\left(1+Z_{I I}\right)}
$$

$$
\begin{aligned}
& N U T_{I}=\frac{1}{1+Z_{I}} \ln \frac{1}{1-E_{I}\left(1+Z_{I}\right)} \\
& E_{I}=\frac{1-\exp \left[-\left(1+Z_{I}\right) N U T_{I}\right]}{1+Z_{I}} \\
& E_{I I}=\frac{1-\exp \left[-\left(1+Z_{I I}\right) N U T_{I I}\right]}{1+Z_{I I}}
\end{aligned}
$$

\subsection{Overall heat transfer coefficient}

For our study, we have two overall heat transfer coefficients, the first one concerns both fluids in the central tube and the internal annulus and the second corresponds to both fluids in the annular passages (intermediate and outside). Their expressions are respectively given by the following expressions:

$\frac{1}{K_{I}}=\left(\frac{1}{h 1}+R_{i, f 1}\right) \frac{d_{e 1}}{d_{i 1}}+R_{p 1} \frac{d_{e 1}}{d_{i 1}}+R_{e, f 1}+\frac{1}{h_{21}}$

$\frac{1}{K_{I I}}=\left(\frac{1}{h 23}+R_{i, f 2}\right) \frac{d_{e 2}}{d_{i 2}}+R_{p 2} \frac{d_{e 2}}{d_{i 2}}+R_{e, f 2}+\frac{1}{h_{3}}$

The heat transfer coefficient by convection is calculated according to the Nusselt number.

$h=\frac{\lambda N u}{d_{h}}$

The Nusselt number in tubes is given according to the flow regime by the following correlations [16]:

$N u=\left[3.657+\frac{0.0677\left(\operatorname{Re} \operatorname{Pr} \frac{d_{i}}{L}\right)^{1.33}}{1+0.1 \operatorname{Pr}\left(\operatorname{Re} \frac{d_{i}}{L}\right)^{0.67}}\right]$

b- for $2300<\operatorname{Re}<10^{5}$, we apply Gnielinski's relation [16]:

$N u=\left[\frac{\left(\frac{f}{8}\right)(R e-1000) P r}{1+12.7\left(\frac{f}{8}\right)^{\frac{1}{2}}\left(\operatorname{Pr}^{\frac{2}{3}}-1\right)}\left(1+\frac{d_{i}}{L}\right)^{0.67}\right]$

$f=\left(1.82 \log _{10} R e-1.64\right)^{-2}$

\subsection{Pressure drop calculation}

The total pressure drop in the triple concentric-tube heat exchanger is obtained by adding all the pressure drops (inlet, singular and by friction), thus we obtain the following expression [15].

$$
\begin{aligned}
& \Delta P_{T}=\Delta P_{f}+\Delta P_{e} \\
& \Delta P_{T}=\Omega \frac{L}{2 d_{h}} \frac{m^{2}}{\rho S_{P}^{2}}\left(\frac{\mu_{p}}{\mu}\right)^{0.14}+\frac{3 m^{2}}{4 \rho S_{p+}^{2}}
\end{aligned}
$$




\subsection{Calculation of costs}

The objective of this paper is the estimation and the comparison of the total costs of triple concentric-tube heat exchangers $C_{t o t}$ for the same thermal load but for the heat exchangers having different intermediate and central tube diameters. The total cost of the heat exchanger is given by [23]:

$$
\mathrm{C}_{\text {tot }}=\mathrm{C}_{\mathrm{i}}+\mathrm{C}_{\mathrm{e}}
$$

Capital costs (construction of the heat exchanger) $C_{i}$, which depends on the heat exchanger surface, which varies with the central tube diameter [15].

$\mathrm{C}_{\mathrm{i}}=\mathrm{a}_{1}+\mathrm{a}_{2} \mathrm{~S}^{\mathrm{a} 3}$

For a stainless-steel heat exchanger, we set by agreement [15]: $\mathrm{a}_{1}=8000$ DZD, $\mathrm{a}_{2}=259.2$ DZD. $\mathrm{m}^{-2}$ and $\mathrm{a}_{3}=0.9$.

The electric energy cost of pumping is established according to the invoice of Sonelgaz applied for factories, craftsmen and factories working in three-phase tension of 380 $\mathrm{V}[15]$.

$\mathrm{C}_{\mathrm{e}}=\sum_{\mathrm{k}=1}^{\mathrm{n}_{\mathrm{TR}}} \frac{\mathrm{CTE}}{(1+\mathrm{i})^{\mathrm{k}}}$

By agreement, we take $\mathrm{i}=0$.

The electric power expenditure $P$ by pumps is given by:

$P=\frac{1}{\eta}\left(\frac{m_{1}}{\rho_{1}} \Delta P_{1}+\frac{m_{2}}{\rho_{2}} \Delta P_{2}+\frac{m_{3}}{\rho_{3}} \Delta P_{3}\right)$

\section{RESULTS}

The obtained results by a calculation code of triple concentric-tube heat exchanger (TTC) developed in the Laboratory of Studies of Industrial Energetic Systems are given below in the form of graphs. This allows us to distinguish better the effects of the various geometrical and hydraulic parameters on the performances and the costs of triple concentric-tube heat exchangers according to the various flow-rates of the fluids and diameters of the heat exchanger tubes. On one hand, we validated our results with the experimental results obtained by Batmaz [13-14,24] and on the other hand, we assumed the thermophysical properties of the fluids constant to study the effects of the physical quantities quoted below on the performances and the costs of triple concentric-tube heat exchangers by comparing our results with those of Unal [8]:

$\checkmark \quad 1$ - Effect of the intermediate tube radius of the heat exchanger on the thermal and electric power expenditures and the economic costs.

$\checkmark$ 2- Effect of the central tube radius of the heat exchanger on the thermal and electric power expenditures and the economic costs.

3- Effect of the central tube radius by changing the intermediate tube diameter of the heat exchanger on the power expenditure and the economic costs.

$\checkmark \quad$ 4- Effect of the flowrate passing in the intermediate tube of the heat exchanger on the power expenditure and the economic costs.

\subsection{Validation of results}

The figure 3 represent the three fluid temperature profiles (internal, intermediate and external) along the triple concentric-tube heat exchanger in co-current and countercurrent flows. The obtained results are validated by comparison to the experimental study of Batmaz [13-14,24].

The temperature rise of the cooling fluids " 1 " and " 3 " which are similar (glycol), is not the same as the flow cross sectional area and the two flow velocities are different, Figure 3. A temperature rise of glycol flowing in the outer annular passage is higher than that of glycol flowing in the central tube in cocurrent and counter-current arrangements.

In co-current flow and a distance of about $17 \mathrm{~m}$ from the inlet of the exchanger the product temperature intersects the temperature of the glycol circulating in the outer annular passage, normally the heat transfer will stop, but the temperature of the product continues to fall because its heat is always subtracted by the cold fluid flowing within the central fluid, Figure 3. So, the product temperature becomes lower than the cooling fluid which will warm farther the product instead of cooling it!

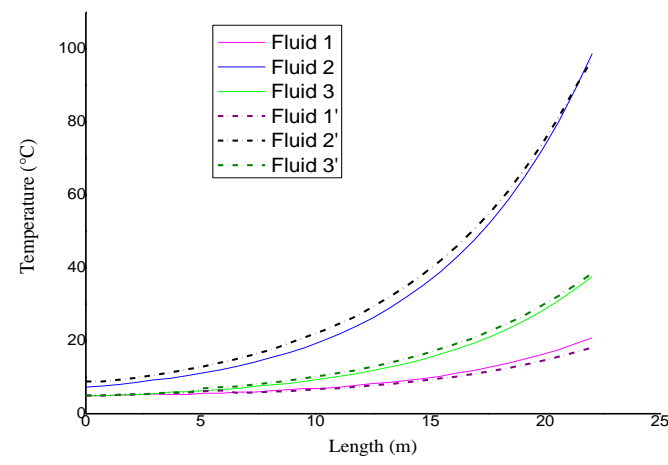

Countercurrent flow

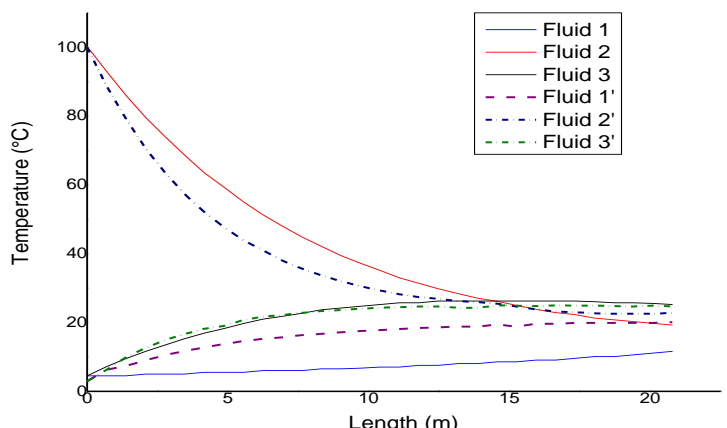

( $)$ Our results (...) Batmaz [22]

Co-current flow

Figure 3. Temperature profiles along a heat exchanger of $22.5 \mathrm{~m}$ of length

\subsection{Effect of intermediate tube radius}

The effect of the intermediate tube radius is represented on Figures 4-6. The studied geometry corresponds to the following dimensions: $r_{i 1}=0.010 \mathrm{~m}$, thickness $r_{e 1}-r_{i 1}=0.001 \mathrm{~m}$, $\mathrm{r}_{\mathrm{i} 2}=(0.020-0.065) \mathrm{m}$, thickness $\mathrm{r}_{\mathrm{e} 2}-\mathrm{r}_{\mathrm{i} 2}=0.002 \mathrm{~m}$, step $=0.005 \mathrm{~m}$, $\mathrm{r}_{\mathrm{i} 3}=0.080 \mathrm{~m}, \mathrm{~L}=30 \mathrm{~m}, \mathrm{~m}_{2}=3000 \mathrm{~kg} / \mathrm{h}, \mathrm{m}_{1}+\mathrm{m}_{3}=10000 \mathrm{~kg} / \mathrm{h}$ and $\mathrm{m}_{1}=\mathrm{m}_{3}, \mathrm{~T}_{\mathrm{e} 2}=80^{\circ} \mathrm{C}$ and $\mathrm{Te}_{1}=\mathrm{T}_{\mathrm{e} 3}=15^{\circ} \mathrm{C}$. 


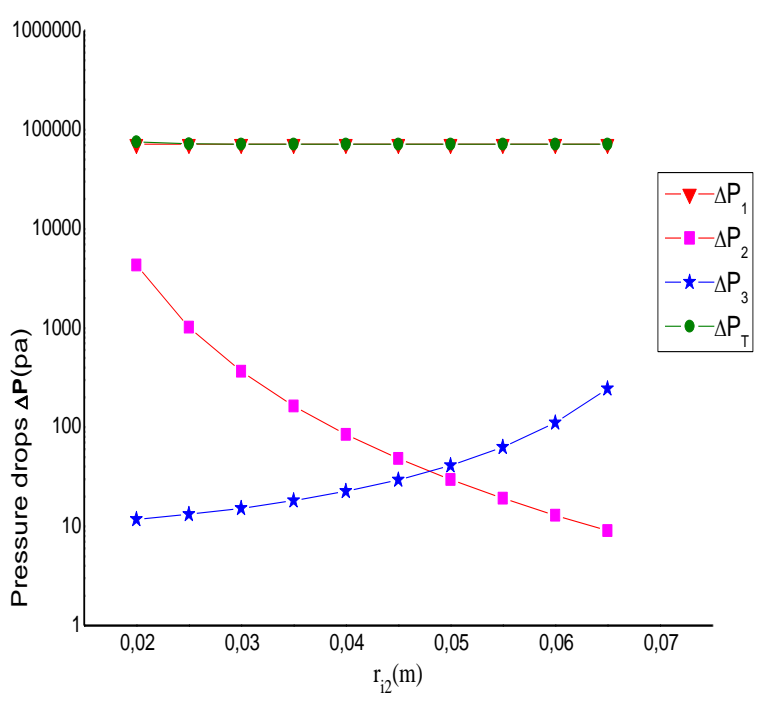

Figure 4. Pressure drop versus the intermediate tube radius

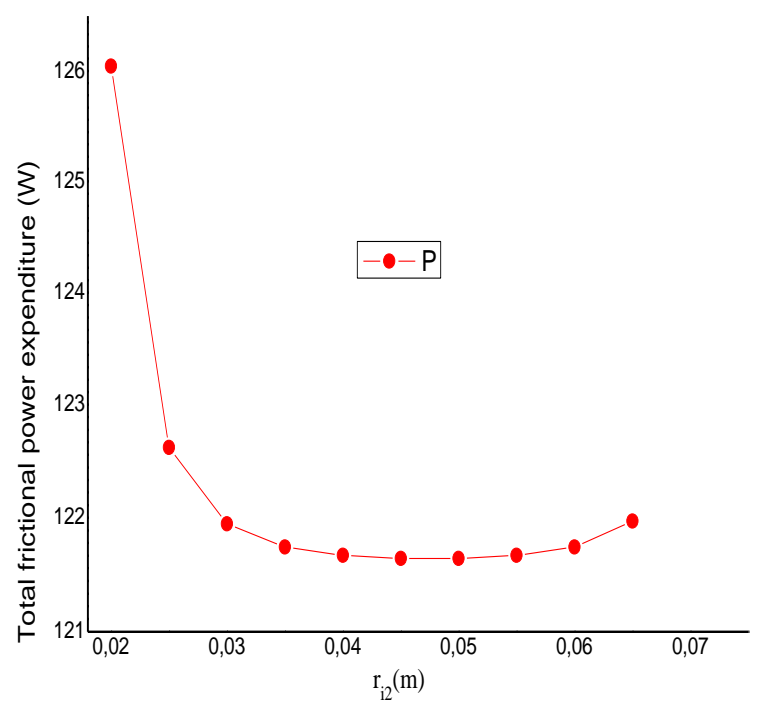

Figure 5. Transferred heat flux versus the intermediate tube radius

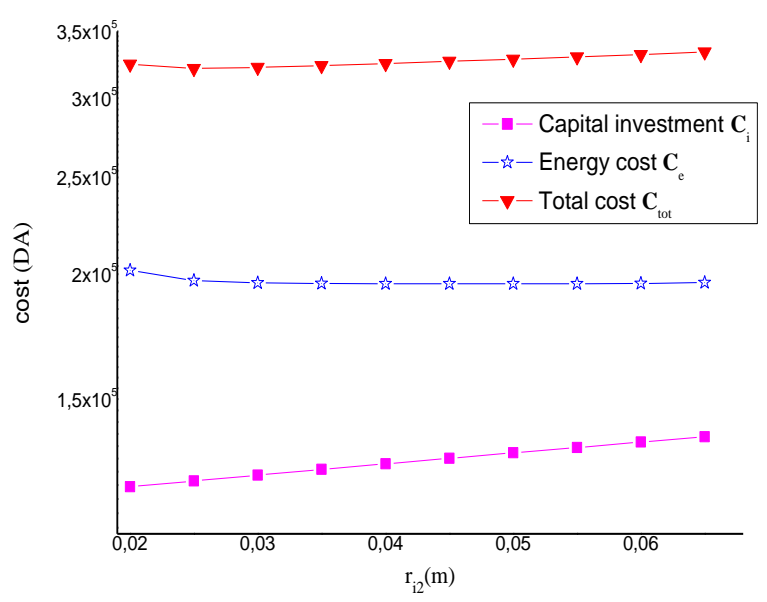

Figure 6. Cost variations versus the intermediate tube radius
The dimensionless number of Reynolds varies according to the variation of the fluid velocity and the hydraulic diameter. By increasing the intermediate tube radius $r_{\mathrm{i} 2}$, the Reynolds number $R e_{2}$ in the internal annulus passage decreases and the Reynolds number $R e_{1}$ in the central tube remains constant. Normally, the Reynolds number $R_{3}$ in the annular passage increases rather than decreases as the fluid velocity increases $v_{3}$, this is due to the decrease in hydraulic diameter $d_{\mathrm{h}}$.

One notice that the heat transfer coefficient by convection $h$ decreases if the hydraulic diameter increases and vice versa. But, the overall heat transfer coefficient $K$ varies proportionally according to the weakest heat transfer coefficient by convection $h$ of the two fluids. With increasing intermediate tube radius $r_{\mathrm{i} 2}$, the heat transfer coefficient by convection $h_{1}$ in the central tube remains constant, the exchange coefficient $h_{2}$ decreases, and the convective coefficient $h_{3}$ increases proportionally with the intermediate tube radius $r_{\mathrm{i} 2}$ because the passage section narrows.

The two overall heat transfer coefficients $\left(K_{1}\right.$ and $\left.K_{2}\right)$ decrease due to the fall of the heat transfer coefficient by convection $h_{2}$ of the fluid passing through the inner annular space which greatly diminishes with radius $r_{\mathrm{i} 2}$.

The efficiency of the heat exchanger decreases and then increases beyond radius $r_{\mathrm{i} 2}=35 \mathrm{~mm}$, this is due to the decrease in the heat transfer coefficient by convection $h_{2}$ with the increase of the interior annular passage section.

The variation of the pressure drops in the three flow sections is similar to the variation of the heat transfer coefficient by convection, Figure 4.

We notice that the power expenditure in the heat exchanger and the energy costs decrease with the intermediate tube radius until a minimal value for $\mathrm{r}_{\mathrm{i} 2}=0.045 \mathrm{~m}$ then increase again with the intermediate tube radius $\mathrm{r}_{\mathrm{i} 2}$, Figures 5 . The pumping power and its cost decrease rapidly and reach a minimum value in the middle of the vein.

The heat exchanger cost increases proportionally with the intermediate tube radius $r_{\mathrm{i} 2}$, Figure 6 . The total cost (functioning and investment) of the heat exchanger has a minimal value for the intermediate tube radius $r_{i 2}=0.025 \mathrm{~m}$, there is now only one optimal radius (radius closest to the central tube radius), Figure 6 .

\subsection{Effect of central tube radius}

The effect of the central tube radius is represented on Figures 7-10. The studied geometry corresponds to the following dimensions $r_{i 1}=(0.010$ to 0.055$) \mathrm{m}$, thickness $r_{\mathrm{e} 1}$ $\mathrm{r}_{\mathrm{i} 1}=0.001 \mathrm{~m}$, step $=0.005 \mathrm{~m}, \mathrm{r}_{\mathrm{i} 2}=0.060 \mathrm{~m}$, thickness $\mathrm{re}_{2}-$ $\mathrm{r}_{\mathrm{i} 2}=0.002 \mathrm{~m}, \quad \mathrm{r}_{\mathrm{i} 3}=0.080 \mathrm{~m}, \quad \mathrm{~L}=30 \mathrm{~m}, \quad \mathrm{~T}_{\mathrm{e} 2}=80 \quad{ }^{\circ} \mathrm{C}$ and $\mathrm{Te}_{1}=\mathrm{T}_{\mathrm{e} 3}=15^{\circ} \mathrm{C}, \mathrm{m}_{2}=3000 \mathrm{~kg} / \mathrm{h}, \mathrm{m}_{1}+\mathrm{m}_{3}=10000 \mathrm{~kg} / \mathrm{h}$ and $\mathrm{m}_{1}=$ $\mathrm{m}_{3}$.

By increasing the central tube radius $r_{\mathrm{il}}$, the Reynolds number $R e_{1}$ decreases proportionally as the flow rate decreases (increase in passage section), the Reynolds number $R e_{2}$ of the annular passage decreases because the hydraulic diameter decreases and Reynolds number $R_{3}$ remains constant because of the annular passage section and the fluid velocity are constant. In this case, the heat transfer coefficient by convection decreases in the central tube and rises in the annular gap because of the decrease in the passage section. The heat transfer coefficient by convection remains constant in the outer annular passage. The overall heat transfer coefficient is a function of the lower heat transfer coefficient by convection, thus increasing of the central tube radius, the overall heat 
transfer coefficient $K_{1}$ decreases ( $h_{1}$ decreases) and the overall heat transfer coefficient $K_{2}$ increases ( $h_{2}$ increases), Figure 7.

The efficiency increases with increasing radius $r_{i 1}$, the inner annular passage section decreases the flow velocity $v_{2}$ and the heat transfer coefficient by convection increases thereby increasing the hot fluid cooling.

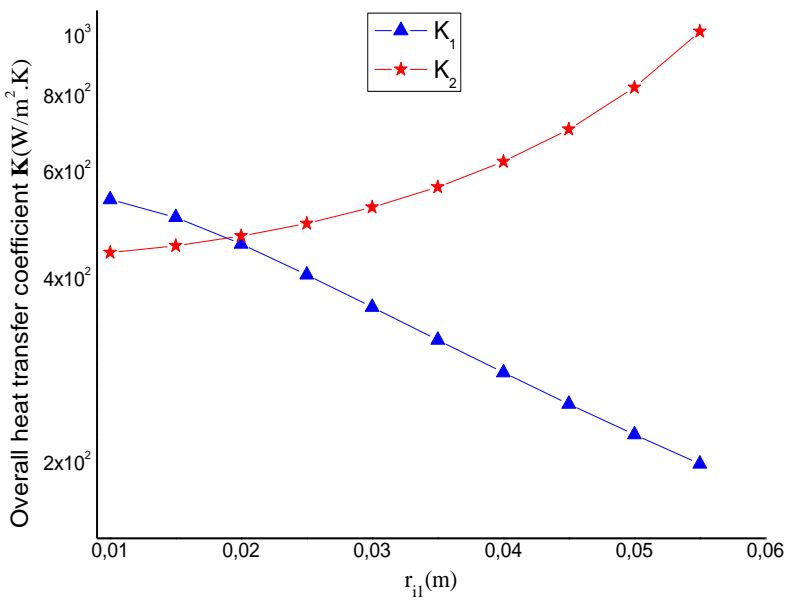

Figure 7. Overall heat transfer coefficient versus the central tube radius

The variations of pressure drops $\left(\Delta p_{1}, \Delta p_{2}\right.$ and $\left.\Delta p_{3}\right)$ are similar to those of convective heat coefficients $\left(h_{1}, h_{2}\right.$ and $\left.h_{3}\right)$, Figure 8 . The minimum total pressure drops and the total expenditure cost to defeat pressure drops correspond to the radius $r_{\mathrm{i} 1}=45 \mathrm{~mm}$, that is at the intersection of the three curves of the pressure drop, Figures 8.

The investment cost increases with the increase of the central tube cost, Figure 9. The total cost is minimal for the central tube radius $r_{\mathrm{i} 1}=25 \mathrm{~mm}$ (about the middle of the intermediate tube radius), Figure 9.

The results given in Figure 10, are obtained upon variation of radii of the central tube and the intermediate tube, they are very close and similar to the results obtained by Unal [8].

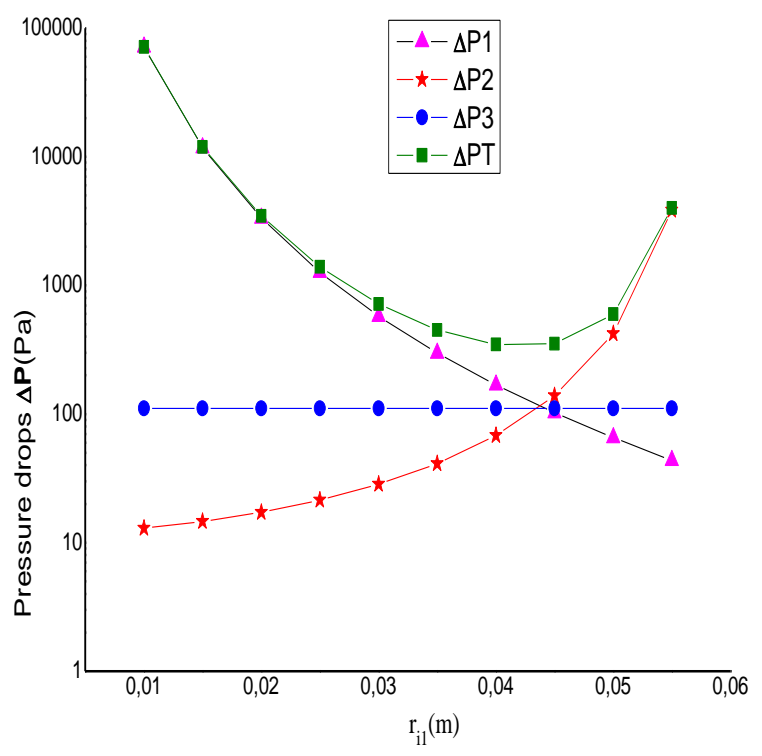

Figure 8. Pressure drop versus the central tube radius

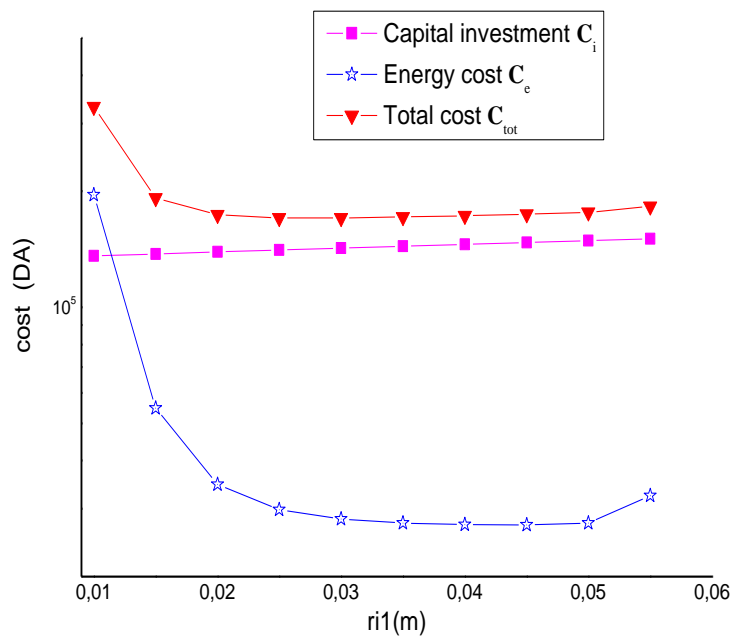

Figure 9. Costs versus the central tube radius

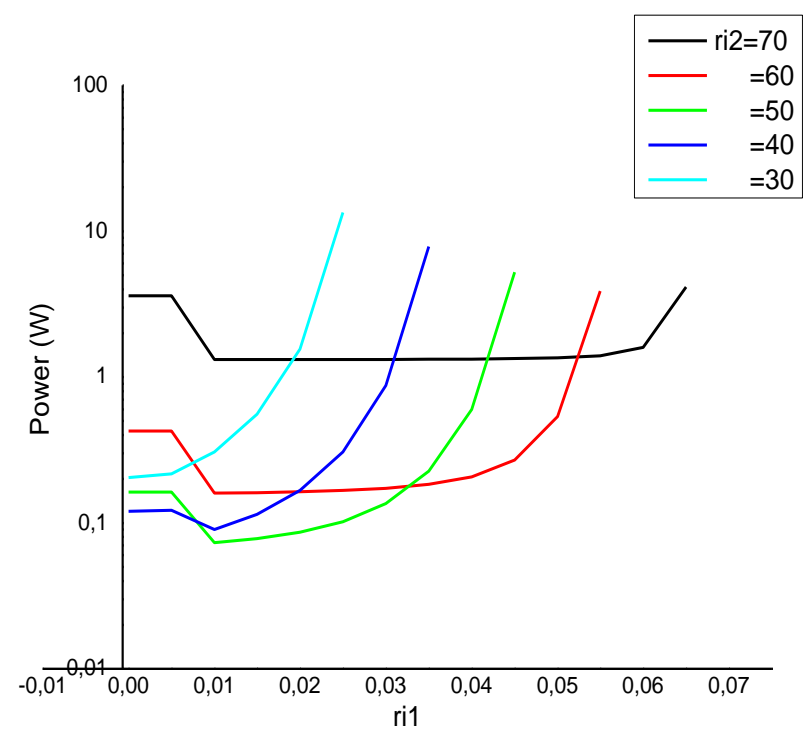

Figure 10. Power expenditure versus the central tube radius

\subsection{Effect of central and intermediate tube radius}

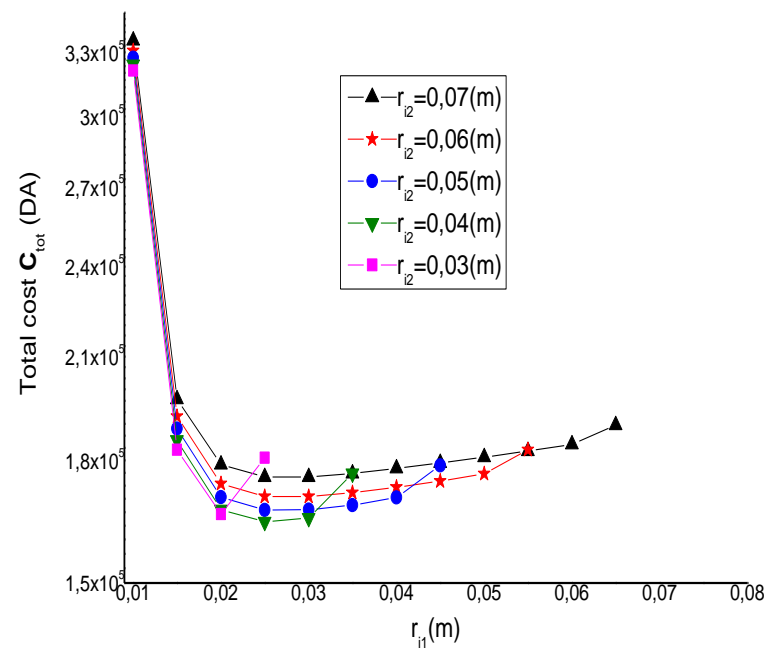

Figure 11. Total cost versus the central tube radius 
The effect of central and intermediate radii is represented in Figures 11-12. The studied geometry corresponds to the following dimensions: $r_{i 1}=(0.010-0.065) \mathrm{m}$, thickness $r_{\mathrm{e} 1}$ $\mathrm{r}_{\mathrm{i} 1}=0.001 \mathrm{~m}$, step $=0.005 \mathrm{~m}, \mathrm{r}_{\mathrm{i} 2}=(0.030,0.040,0.050,0.060$ and 0.070$) \mathrm{m}$, thickness $\mathrm{r}_{\mathrm{e} 2}-\mathrm{r}_{\mathrm{i} 2}=0.002 \mathrm{~m}, \mathrm{r}_{\mathrm{i} 3}=0.080 \mathrm{~m}, \mathrm{~L}=30 \mathrm{~m}$, $\mathrm{Te}_{2}=80{ }^{\circ} \mathrm{C}, \mathrm{T}_{\mathrm{el}}=\mathrm{T}_{\mathrm{e} 3}=15^{\circ} \mathrm{C}, \mathrm{m}_{2}=3000 \mathrm{~kg} / \mathrm{h}, \mathrm{m}_{1}+\mathrm{m}_{3}=10000$ $\mathrm{kg} / \mathrm{h}$ and $\mathrm{m}_{1}=\mathrm{m}_{3}$.

The efficiency increases with increasing radii $r_{\mathrm{i} 1}$ and $r_{\mathrm{i} 2}$, the inner annular passage section decreases, the flow velocity $v_{2}$ and the heat transfer coefficient by convection increases thereby increasing the hot fluid cooling. The total cost is minimal when the central tube radius is equal to the middle of the intermediate tube radius, Figure 11.

\subsection{Effect of the flow rate passing in the intermediate annulus}

The effect of the flow rate passing in the intermediate annulus is represented in Figure 12. The dimensions of the studied geometry are: $r_{i 1}=(0.01-0.055) \mathrm{m}$, thickness $r_{\mathrm{e} 1}$ $\mathrm{r}_{\mathrm{i} 1}=0.001 \mathrm{~m}$, step $=0.005 \mathrm{~m}, \mathrm{r}_{\mathrm{i} 2}=0.06 \mathrm{~m}$, thickness $\mathrm{re}_{2}-\mathrm{r}_{\mathrm{i} 2}=0.002$ $\mathrm{m}, \mathrm{r}_{\mathrm{i} 3}=0.08 \mathrm{~m}, \mathrm{~L}=30 \mathrm{~m}, \mathrm{~m}_{1}+\mathrm{m}_{3}=10000 \mathrm{~kg} / \mathrm{h}, \mathrm{m}_{1}=\mathrm{m}_{3}, \mathrm{~T}_{\mathrm{e} 2}=80$ ${ }^{\circ} \mathrm{C}$ and $\mathrm{Te}_{1}=\mathrm{T}_{\mathrm{e} 3}=15^{\circ} \mathrm{C}$.

The optimum radius of the central tube corresponding to the minimum electrical power pumping decreases with the increase of the hot fluid flowing in the central tube, Figure 11.

The optimal radius of the central tube of the minimum total cost is independent of the hot fluid rate, Figure 12. The efficiency increases with the radius $r_{\mathrm{i} 1}$ because the convective heat transfer coefficient increases and lowering temperature decreases with the increase of the hot fluid rate.

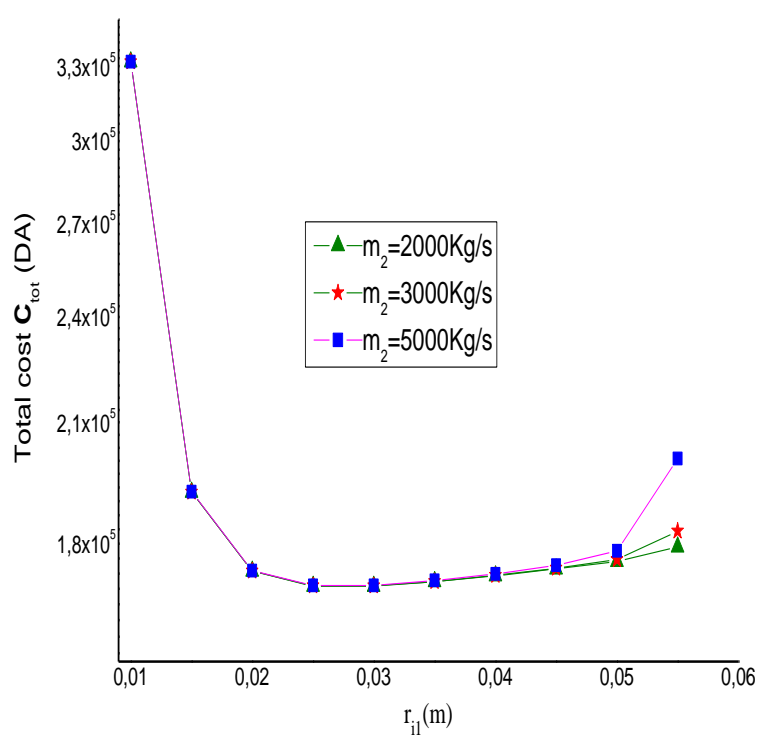

Figure 12. Total cost versus central tube radius

Now we have only one optimum diameter which corresponds to the minimum total cost, unlike previous studies [6-8], where we had two optimal diameters, the first diameter corresponds to the maximum efficiency and the second diameter corresponds to the minimal energy consumption required to overcome the pressure drop in the heat exchanger.

In all the cases examined, the investment costs have a higher percentage than the total frictional power expenditure cost $\left(C_{e}\right)$, for $m_{2}=3000 \mathrm{~kg} / \mathrm{h}$, energy costs $\left(C_{e}\right)$ are less than $10 \%$ and the investment costs $\left(\mathrm{C}_{\mathrm{i}}\right)$ are greater than $90 \%$ of $\left(\mathrm{C}_{\text {tot }}\right)$, so the reduction in investment costs leads to an economy of the total cost. This confirms the effectiveness of our proposed economic approach which is a more realistic optimization than the majority of the approaches used in the literature where it exits two optimal central tube diameters, the first corresponds to the heat exchanger efficiency and the last one to the total frictional expenditure.

\section{CONCLUSION}

The technical-economic calculation is required for the design of economic hydrogen engine.

The computer program developed in Fortran language provides us the optimal diameter corresponding to the minimum total cost of the heat exchanger (production and pumping costs to overcome pressure drops) for the same transferred thermal power. The obtained temperature fields help us to choose the desired temperatures. The effectiveness of the heat exchanger increases proportionally with the central tube radius. The developed model can be an excellent tool to optimize the efficiency of triple concentric tube heat exchangers, and therefore the consumption of energy and matter. We have one optimum diameter, unlike previous studies, where they had two different optimal diameters, the first corresponds to the maximal heat exchanger efficiency and the last one to the minimal energy consumption required to overcome the pressure drop in the heat exchanger.

\section{ACKNOWLEDGMENT}

We thank the Algerian Ministry of Higher Education and Research for the realization of this study.

\section{REFERENCES}

[1] Bond WH. (1991). Leak-safe hydrogen/air heat exchanger in an ACE system, US Patent(5048597).

[2] Baadache K, Bougriou C. (2015). Optimisation of the design of shell and double concentric tubes heat exchanger using the genetic algorithm. Heat and Mass Transfer 51: 1371-1381. https://doi.org/10.1007/s00231015-1501-y

[3] Bougriou C, Baadache K. (2010). Shell-and-double concentric-tube heat exchangers, Heat and Mass Transfer 46: 315-322. https://doi.org/10.1007/s00231-010-0572-z

[4] Litouche B, Bougriou C. (2017). Effects of convective instabilities on heat exchangers, International Journal of Hydrogen Energy 42(8): 5381-5389. https://doi.org/10.1016/j.ijhydene.2017.01.203

[5] Zuritz CA, (1990). On the design of triple concentrictube heat exchanger, Journal of Food Process Engineering 12: 113-130. https://doi.org/10.1111/j.17454530.1990.tb00045.x

[6] Unal A. (1998). Theoretical analysis of triple concentrictube heat exchangers, part-1: mathematical modelling, Int. Communications in Heat and Mass Transfer 25: 949958. https://doi.org/10.1016/S0735-1933(98)00086-4

[7] Unal A. (2003). Effectiveness-NTU relations for triple concentric-tube heat exchanger, Int. Communications in Heat and Mass Transfer 30: 261-272. https://doi.org/10.1016/S0735-1933(03)00037-x 
[8] Unal A. (2001). Theoretical analysis of triple concentrictube heat exchangers, part-2: case studies, Int. Comm. in Heat and Mass Transfer 28. pp. 243-256. https://doi.org/10.1016/S0735-1933(01)00231-7

[9] Garcia-Valladares O. (2004). Numerical simulation of triple concentric-tube heat exchangers, Int. Journal of Thermal Sciences 43: 979-991. https://doi.org/10.1016/j.ijthermalsci.2004.02.006

[10] Garcia-Valladares O, Velazquez N. (2009). Numerical simulation of parabolic trough solar collector Improvement using counter flow concentric circular heat exchangers, Int. Journal of Heat and Mass Transfer 52: 597-609.

https://doi.org/10.1016/j.ijheatmasstransfer.2008.08.004

[11] Nema PK, Datta AK. (2006). Improved milk fouling simulation in a helical triple tube heat exchanger, Int. Journal of Heat and Mass Transfer 49: 3360-3370. https://doi.org/10.1016/j.ijheatmasstransfer.2006.03.021

[12] Sahoo PK, Ansari IA, Datta AK. (2005). Milk fouling simulation in helical triple tube heat exchanger, Journal of Food Engineering 69: 235-244. https://doi.org/10.1016/j.jfoodeng.2004.08.014

[13] Batmaz E, Sandeep KP. (2005). Calculation of overall heat transfer coefficients in a triple tube heat exchanger, Heat Mass Transfer 41: 271-279. https://doi.org/10.1007/s00231-004-0546-0

[14] Batmaz E, Sandeep KP. (2008). Overall heat transfer coefficients and axial temperature distribution in a triple tube heat exchanger, Journal of Food Process Engineering 31: 260-279. https://doi.org/10.1111/j.1745-4530.2007.00154.x

[15] Caputo AC, Pelagagge PC, Salini P. (2008). Heat exchanger design based on economic optimization, Applied Thermal Engineering 28: 1151-1159. https://doi.org/10.1016/j.applthermaleng.2007.08.010

[16] Lee PS, Garimella SV, Liu D. (2005). Investigation of heat transfer in rectangular microchannels, Int. Journal of Heat and Mass Transfer 48: 1688-1704. https://doi.org/10.1016/j.ijheatmasstransfer.2004.11.019

[17] Basal B, Ünal A. (2013). Numerical evaluation of a triple concentric-tube latent heat thermal energy storage, Solar Energy 92: 196-205. https://doi.org/10.1016/j.solener.2013.02.032

[18] Quadir GA, Jarallah SS, Salman NJ, Badruddin IA. (2013). Experimental investigation of the performance of a triple concentric pipe heat exchanger, Int. Journal of Heat and Mass Transfer 62: 562-566. https://doi.org/10.1016/j.ijheatmasstransfer.2013.03.033

[19] Quadir GA, Badruddin IA, Salman NJ. (2014). Numerical investigation of the performance of a triple concentric pipe heat exchanger, Int. Journal of Heat and Mass Transfer 75: 165-172. https://doi.org/10.1016/j.ijheatmasstransfer.2014.03.042

[20] Singh SK, Mishra M, Jha PK. (2014). Experimental investigation on thermo-hydraulic behavior of triple concentric-tube heat exchanger, Journal of Process Mechanical Engineering, Part-E Vol. 299: 29-308. https://doi.org/10.1117/0954408914531118

[21] Pătrăşcioiu C, Rădulescu S. (2015). Prediction of the outlet temperatures in triple concentric-tube heat exchangers in laminar flow regime case study, Heat and Mass Transfer 51: 59-66. https://doi.org/10.1007/s00231-014-1385-2

[22] Kern DQ. (1950). Process Heat Transfer, McGraw-Hill,
[23] Taal M, Bulatov I, Klemes J, Stehlik P. (2003). Cost estimation and energy price forecast for economic evaluation of retrofit projects, Applied Thermal Engineering 23: 1819-1835. https://doi.org/10.1016/s1359-4311(03) 00136-4

[24] Batmaz E. (2003). Overall heat transfer coefficients and axial temperature distribution of fluids in a triple tube heat exchanger, M. S. Thesis, Faculty of North Carolina State University.

[25] Abdalla G, Halim M, Ashraf ME. (2016). Experimental and numerical investigations of a triple concentric-tube heat exchanger, Applied Thermal Engineering 99: 13031315. https://doi.org/10.1016/j.applthermaleng.2015.12.053

[26] Abdalla G, Halim MA, Ashraf ME. (2017). Enhancement of cooling characteristics and optimization of a triple concentric-tube heat exchanger with inserted ribs, Int. Journal of Thermal Sciences 120: 106-120. https://doi.org/10.1016/j.ijthermalsci.2017.06.002

[27] Valerio G, Rajnish NS, Robert RR. (2017). Numerical prediction of thermal performances in a concentric triple tube heat exchanger, Int. Journal of Thermal Sciences 120: https://doi.org/10.1016/j.ijthermalsci.2017.06.003

[28] Taraprasad M, Biranchi NP, Sudhansu SS. (2017). Experimental investigation of convective heat transfer in an inserted coiled tube three fluid heat exchanger, Applied Thermal Engineering 117: 297-307. https://doi.org/10.1016/j.applthermaleng.2017.02.023

[29] De Rossi F, Marigliano M, Marino C, Francesco M. (2016). A technical and economic analysis on optimal thermal insulation thickness for existing office building in Mediterranean climates, International Journal of Heat and Technology 34: 561-568. https://doi.org/10.18280/ijht.34Sp0251

[30] Pesteei SM, Mashoofi N, Pourahmad S, Roshan A. (2017). Numerical investigation on the effect of a modified corrugated double tube heat exchanger on heat transfer enhancement and exergy losses, International Journal of Heat and Technology 35: 243-248. https://doi.org/10.18280/ijht.350202

[31] Sarma PK, Konijeti R, Subramanyam T, Prasad LSV, Korada VS, Srinivas V, Vedula DR, Prasad VSRK. (2017). Fouling and its effect on the thermal performance of heat exchanger tubes, International Journal of Heat and Technology 35, pp. 509-519. https://doi.org/10.18280/ijht.350307

\section{NOMENCLATURE}

$\begin{array}{ll}\mathrm{a}_{1} & \text { Constant, DZD } \\ \mathrm{a}_{2} & \text { Constant, DZD.m }{ }^{-2} \\ \mathrm{a}_{3} & \text { Constant } \\ \mathrm{C} & \text { Heat capacity, W.K } \mathrm{K}^{-1} \\ \mathrm{C}_{\mathrm{e}} & \text { Electric energy cost, DZD } \\ \mathrm{C}_{\mathrm{i}} & \text { Capital cost, DZD } \\ \mathrm{Cp} & \text { Specific heat, J.kg }{ }^{-1} \cdot \mathrm{K}^{-1} \\ \mathrm{CTE} & \text { Total cost of the electrical energy by slice, } \\ & \text { DZD.kWh }{ }^{-1} \\ \mathrm{C}_{\text {tot }} & \text { Total cost, DZD } \\ \mathrm{d} & \text { Diameter, m } \\ \mathrm{d}_{\mathrm{h}} & \text { Hydraulic diameter, } \mathrm{m} \\ \mathrm{E} & \text { Efficiency }\end{array}$




\section{Greek letters}

Pressure drop, $\mathrm{Pa}$ ${ }^{2}$. $\mathrm{K}^{-1}$

Slice number

Temperature, ${ }^{\circ} \mathrm{C}$

Heat capacity ratio

Density, kg. $\mathrm{m}^{-3}$

Heat flux, W
Heat transfer coefficient by convection, W.m-

Updating of the electricity price

Overall heat transfer coefficient, $\mathrm{W} \cdot \mathrm{m}^{-2} \cdot \mathrm{K}^{-1}$

Heat exchanger length, $\mathrm{m}$

Masse flowrate, kg.s ${ }^{-1}$

Number of transfer units

Electric power expenditure, $\mathrm{W}$

Thermal resistance, $\mathrm{m}^{2} . \mathrm{K} . \mathrm{W}^{-1}$

Fouling resistance, $\mathrm{m}^{2} . \mathrm{K} . \mathrm{W}^{-1}$

Exchange surface, $\mathrm{m}^{2}$

Flow cross sectional area, $\mathrm{m}^{2}$

Fluid velocity, $\mathrm{m} . \mathrm{s}^{-1}$

Temperature difference, ${ }^{\circ} \mathrm{C}$

Pump efficiency, \%

Heat conductivity, W. $\mathrm{m}^{-1} \cdot \mathrm{K}^{-1}$

Dynamic viscosity, Pa.s

\section{Dimensionless numbers}

$\begin{array}{ll}\mathrm{Nu} & \text { Nusselt number, } N u=\frac{h d_{h}}{\lambda} \\ \mathrm{Pr} & \text { Prandtl number, } \operatorname{Pr}=\frac{\mu C p}{\lambda} \\ \mathrm{Re} & \text { Reynolds number, } R e=\frac{\rho V d_{h}}{\mu}\end{array}$

\section{Subscript}

e

f

I

II

i

$\max$

$\min$

$\mathrm{p}$

$\mathrm{s}$

$\mathrm{T}$

1

2
Entrance, outside

Friction

Heat exchanger formed by the internal tube and the central tube

Heat exchanger formed by the central tube and the outside tube

Inside

Maximum

Minimum

Metal wall

Exit

Total

Fluid or wall relative to the internal tube

Fluid or wall relative to the intermediate tube

Fluid or wall relative to the external tube 